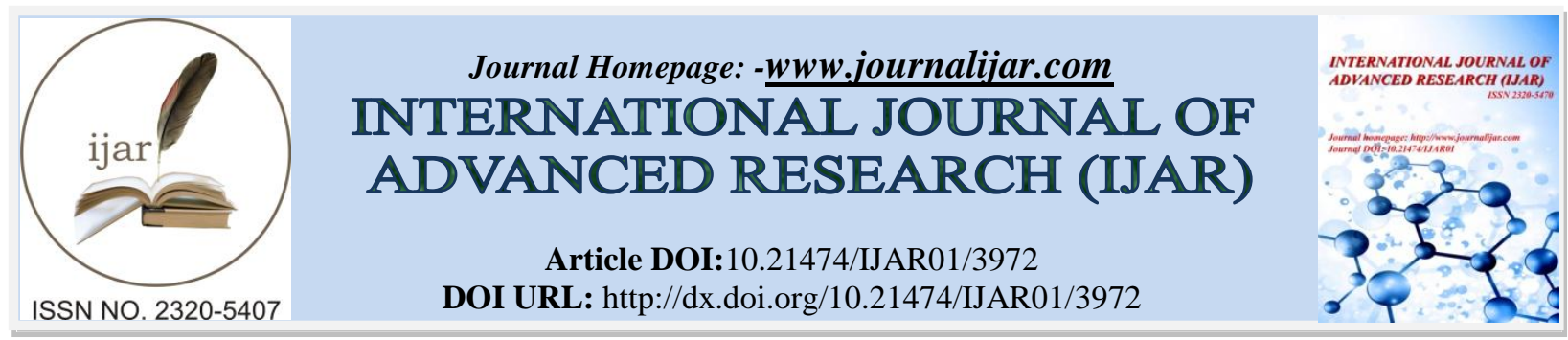

RESEARCH ARTICLE

\title{
AN OUTLOOK ON THE INFORMATION SOCIETY'S ELEMENTS, OPPORTUNITIES, AND STRUCTURAL CHALLENGES RELYING ON THE ISLAMIC REPUBLIC OF IRAN.
}

Younes. Froozan ${ }^{1}$ and Abdolreza Alishahi ${ }^{2}$.

1. PhD Student in Communication Sciences of Allameh Tabatabaei University,Tehran, Iran.

2. Master of Political Science, University of Isfahan, Isfahan,Iran

\section{Manuscript Info}

Manuscript History

Received: 18 February 2017

Final Accepted: 06 March 2017

Published: April 2017

Key words:-

Information Society, Communicative

Networks, Development, Iran

\section{Abstract}

At the present times, information has turned into the symbol of an era that we live in. these days, the information explosion, a revolution on information technology or even an information society are among the frequent discussion around the world. The term of information society is reflecting the development of new information technologies and reorganization of society around the information flow. Nowdays, with the informatics networks, all information are available to any format faster than previously were. The process is growing faster due to the increasing use of information highways, and the information is emerging as an increasingly precious commodity in today's global civilization. The establishment of such a society can lead to produce new industries, jobs and products. The fact by which society's economical bases may be encountered with some new manifestations. The infrastructures of information society can be classified as follow;

1. Telecommunication infrastructures;

2. Knowledge-based infrastructures; and finally

3. Technological infrastructures of information.

Indeed, first of all, the information community is the result of several hardware and software links rooted in the social-technical structure of that society. Here, some points of them can be mentioned: Digital, the rise of modern computer languages including Gmail; the development of all telecommunication network components (optical cables, satellites, telephones); and at the last, the linkage all of them within structure known as internet, by which the network practically gets rid of the previous constraints (organizational, local, national). The information society containing the new types of communications is subjected to some specific tools like internet among them dating, conferences, and electronic debates can be pointed out. This phenomenon has created a variety of virtual communities in cyberspace. Accordingly, It can be said that the spaces with modern elements and without geographical and political boarders affect the social relations. As we shall see, the results of the article indicate that the advent of information society coincides with several phenomena such as;

a. Globalization of the economy;

b. The rise of knowledge-based economy; and lastly 
The development and deeply application of communicative networks and digital consequences.

Copy Right, IJAR, 2017,. All rights reserved.

\section{Introduction:-}

In today's world, the production of information and technical knowledge is a process coinciding with the access to classified information and applying of it in economic and social development is typically regarded as an advantage. The results acquired from the researches, making some theories, strategic experiments, development of concepts, observations, as well as technologies can be presented to the other researchers as a usable form. The information society is a society with the information services of mass media moving forward faster other communities along with the supremacy of the accumulated empirical and pure knowledge; a society in which the communication is a real driving force for evolution to each individual in order to practically get to information without any boundaries; and in that society, the communication of the global information network have been replaced the global telephony services and the production of information values are determinant the fellowship to develop. In an information society, the patterns of working life, leisure times, educational system, and business area are specifically affected by progress in information and technical knowledge. The phenomenon is rooted in the increasing growth of mass production of information over a wide range of the mass media whose majority is also appearing in the electronic form.

\section{Explaining the history of the information Society:-}

Since 1970s, there have been extensive developments in the contexts of information and communication in the West, particularly in some advanced countries. Around 1980s, computers entered in the homes and offices; the communication sector was added to the economic formalities, and global trade offs was taking place day and night via communication networks more quickly, so it was a decisive factor in people's life. In 1990s, peoples presented a more performance with fewer work hours and official works were performed with no paper exchange just like electronic cottage that is more than a myth in that decade. The new classification has been found with the feature of information poverty due to a new form of domination and electronic dominance in the global arena. Therefore, a modern era known as information one is emerging (shokrkhah, 1384; 18-23).

In those days, there is not only an increase to the information mass or activities associated to communication, but also a series development associated to an agricultural-based fellowship to an industry-based and then to an information-based community to be turned, is obvious. Although, the definition of information society doesn't refer to practices in particular, there is no doubt it is linked to capitalism and the Western societies. Due to authoritarian and totalitarian tendencies in The Socialists, they could not be a cause the information society can be formed. So, they may be the mass of information and dissemination of them using the Western communication technologies which were followed the former Soviet Union and Eastern European countries to be disintegrated. Now, the danger is that the dissemination and processing of the information may be highly placed in the hands of a few dominant countries and also the loss of freedom of thought and independent decision making would be a serious threat for other countries across the world. Accordingly, with the international information communication, there is an explicit dominance for developed nations, and the information issued by them is higher than the imported data from others especially from developing countries, and/or communities in Central and Eastern Europe (Bedi, 2001; 13-15).

In today's communities, we particularly see two sub-groups named rich and poor in terms of information to be benefited. Thus, when the information flow has more mobility in the society, those who are economically and socially in a better condition can seize the information more rapidly than the poor. So with the increase of data differentiation, the discrimination between political-economical-scientific top classes and sub-classes will be more and more. According to the dangers of capitalist rule at the last decade of $20^{\text {th }}$ century, Leone reminds the risk of power concentration at the information society with the knowledge about the monitoring of information technologies would be a problem in the future. He is not favorable to the development of information towards modern economics, because not only he knows a problematic affair for many occupations can be devoted based on information, but also the flow of job breakdown into information and non information classes as a result of all aspects dependency of activities to the information will follow many problems and doubts (Heeks, 2006: 3-4). 


\section{Criteria for the information societies:- Economical criterion:-}

it can be mentioned the economical information as a first measure and a means to progress toward information society which is due to the social and economic developments from 1960 to the present. Studies conducted in this area by MachLoop \& Port led to some new attitudes on the role of information in developed and developing countries' economy; the concept of a new information topic which is representing a transient economy from a basic condition of an economy based on agriculture to industry and then to information-based economy. This leads to describe the elements of the economy with phrases such as: industry information, market information, and intelligence staff, which have now entered into daily speech. So, some alterations are caused by the same issue on the structure of employment with the expanding occupations in the field of personal, commercial, educational, health, communication, and financial services. Following Yunsher statements, the main factor to communicate, the growth of bureaucracy and unproductive human resources was derived from industrial advances that increased economical complexity, the necessary proficiency -orientation in each discipline, and in this way, led to employ the information professionals (Gamham, 2003: 28-29).

\section{Technology criterion:-}

we are living in an age that all data and information in different contexts including taxation, national security, registration of deeds, credit cards, medicines and so on are delivered as a digital data in all communities, and required data can be acquired in accordance with national and international security through applying computer and its relationship with defensive satellites and prognostic systems to predictive system for weather condition and maritime. Although the progress of technology is not by itself the sufficient condition for achieving an information society, but it is considered an essential prerequisite for that. The key to this achievement is depend on to what extend these technologies can be separated from daily lives of citizens. The study performed by Hilal is indicating a wide application of advanced technologies like optical computers, qualified specialists, technical knowledge-based communication system and electronic libraries during the years after 2000. At the same time, communication services as a consequence of social consciousness transformation have gained popularity in the form of distance learning in information channels, remote press conferences, as well as trade and marketing via computer networks (Beck, 2009: 197-201).

\section{Social criterion:-}

An information-based social transformation which include the effect of freedom for codifying the law governing the exchange of information in which the establishment of electronic information and communication networks can bring about family and community revitalization. The isolation of the information-less poor stratum inside electronic community owing to re-establish them in the information society who are exploited by employers as well as ignoring the rights of the people on the contracts to conclude occur again in a new form. Masuda ${ }^{1}$ (2000) pays his attention to plan that information society in which the main ground of the information values prevails over the material values, so in the society's economy, the information assets and technical know-how are superior to materials' resources (Masuda, 2000: 18-19).

\section{Political criterion:-}

The power concentration, political influence, and social developments based on information is clear reason on advantages in order to set up an information pole that can make the fundamental political changes through the news coverage (like what happened for the Soviet Union and the Eastern blocks). If we look to play the latest events in the mass media in terms of poverty or richness information, then there are two categories of audience before us; on one hand there are passive audiences who are just consumers together with the mass media, and on the other hand there are a small number of top nations, excelled individuals in the countries, active producers, and electronic information users (Duff, 2000: 37-40).

\section{Cultural criterion:-}

Many observers believe that the progress in the information society leading to some developments, have a number signs that are manifested in the cultural values, however it should be noted that there is a different reaction about sophisticated technologies between various nations and even the global culture of electronics is susceptible to adopt local and national influences. Indeed, the development and extensive interaction between cultures is something to be

\footnotetext{
1.Yonji Masuda
} 
took place, not the so-called a newly formed culture leading to substantial changes on lifestyle all around the world (Ibid: 42). There have been frequently the danger one culture can be dominated means a culture based on the west materialist values may replace the national culture and can bring absurdity to the world because of cultural poverty. Though it may be a news cause different reactions in various countries but ignoring the potential adverse effects of the universal flow of information on identity and cultural diversity of all countries is considered to be dangerous, because it may lead to accept the culture of recklessness and openness in which there is a great emphasis on the exchange of diverse information particularly with focus on the areas of social, political, economic, and cultural. The brain drain is a phenomenon that leads to the migration of engineers and researchers from developing nations to developed and industrialized countries, and the best skilled specialists in the field of science and technology migrate to wealthy States in the West. So those nations who loss the powers are experiencing a decrease in their technology. Modernization strategies in Third World countries often produce the increased foreign debts and improved international remote communication instead of developing indigenous information and telecommunication network. Major telecom companies in their commercial relations with the East are only trying to make local unfair competitions and in this regard, they are looking for unbalanced social developments in the way of remote communications (Moradi, 1388: 258- 271).

The judgment about developing countries in terms of information will establish an obvious contradiction between those who are information-rich against those who are lacking in information. The amount and quality of information required for planning and managing based on statistical information system is much more than that can be centrally assessed and be applied as the same measure. As a result, despite the fact that dominant countries are certainly rich from information perspective, but there is a great doubt on having a real scientific richness by them. In contrast, people in small nations under dominance, can find the richness of a true knowledge. As knowledge and information of people in these nations that is accompanied with some experiences on the shortages, poverty, hardship, sufferings, dependency, and oppression, will be deep, lasting and eternal. If the above mentioned difference between information and knowledge to embrace then the information systems to be expanded quantitatively to any developing country would be absurd and unreasonable, but instead the overall goal should be the quality of the system to got better. In recent days, becoming information means to be internationalization and globalization and this process will always entail the proliferation of the cultures. Naturally, each culture belongs to a particular place or region that involves the comprehensive and accumulated knowledge in the course of generations and is a reflection of talents and features of a group against other groups manifested in language and dialects that bring about a sense of belonging to a land and ancestral identity. It is just because of this feeling that a culture cannot be used as a private or commercial tool (Vadadi \& Dashti-RahmatAbadi, 1386: 35-40). Besides, the most common and important criteria for an information society are as follow:

\section{Technology:-}

Obviously, technology has had a substantial role on changes occurred during three past decades. For this, the most preferred definition about information society is established in line with tremendous innovation of technology (Webster, 1380:20). Frank Webster ${ }^{2}$ in his definition of information society relying on technology element articulates, spectacular advances on processing, storage, and transmission of information has led to the use of information technologies in all aspects of social life (Bahrampour, 1383: 73- 76). By entering computers in all areas of human life such as offices, homes, automobiles, televisions, children's toys, cheapening the processing technologies, the storage of information through computers and its impact on remote communications together with creating the global networks all and all have produced a great evolution in human life. Information networks are influencing on all dimensions of human life in not too distant future; and in the next few years, few in numbers of those who don't use of them or these technologies have not a role in their lives. As a consequence, being a lot of innovations in information and communication technologies is one of the elements in the emergence of the information society.

\section{Globalization:-}

Another characteristic or feature that defines the information and networking society is globalization. According to the measure presented by Webster, globalization is a phenomenon that can be realized under information society. Globalization means the world to be jammed and turning it into a single place and/or the accumulation of awareness on the whole to the components. In other words, globalization is the same unifying the world, not its unity and

\footnotetext{
${ }^{2}$-Frank Webster
} 
integration. This interpretation of globalization is based on information and communication technologies. Following that, the information society is a fellowship in which the business of the media and scientific-academic relationships and education will be unified (Webster, 2002: 10-12). With establishing information and communication networks, all users who are applying them find a common language and although they are too away from each other, they are very similar to one another's daily lives in an unexpected way, and they are just different in their tastes, means that the users of these networks feel closer to each other than to neighbors who are nearer to them physically. Thus, it is said, the intelligence community is a compressed and unified world (Ibid: 14).

\section{Information-based carriers:-}

One of the common criteria and features to define information society is a criterion focused on carrier changes. In fact, with a shift from those jobs with physical activities to information-based jobs, i.e. the jobs with intellectual tasks and more skills or in other word, the affairs involved in the practice of production, processing, and distribution of data, the information society has been come into view. Reports from international corporations show that in the last two decades, the growth observed for white-collar jobs or those jobs that are mainly dealt with the production and use of information and the infrastructures supporting them is more than the others (Rabertson, 1380: 12). In modern parlance, the labor market is run by those who are dealing with software and have a role in the course of producing, processing, and distributing the information and are living in the same way. Therefore, with the emergence, and development of information and communication technologies around the world, information work force has risen to a tremendous growth. For this reason, shift in distribution of jobs is considered one of the characteristics of the information society (Webster, 2007: 152).

\section{Media coverage:-}

One of the criteria and parameters related to the occurrence of the information society is the rate of media coverage. The pace of the media coverage that have been actually developed due to extraordinary and unique innovation in information and communication technologies is severely affected the human private life's realm. Advances provided for information and communication technologies have linked TV services with extensive networks of institutions and ultimately to the satellites and are easily available all over the world. Despite, the technologies are not equally accessible to the any point, but the coverage of fresh media from satellite TV to the internet have strongly broadened and have totally made an influence on the globe. Continuous and permanent access to media and that in the modern media the audiences can be both producer and consumer of information have generated a very wide and fast coverage for them (Hillis, 2014: 2-3).

\section{Economic:-}

Based on definition of information society, it seems the economic measure to be as important as the measure of technology. Fritz Machlub ${ }^{3}$ who is one of the pioneers to the issue addresses the scope and growth of information industries in the United States and knows the origin to initiate the scales of information society based on economic conditions. The professor of management, Peter Ducker, 1967 declared that the economics in the United States is shifted from a commodity or product-driven economy to information or data-driven economy. He asserts that knowledge i.e. the same information is the basis for modern economy. In fact, the information not only have economic value, but also they are an economic ground for society, and anyone who is able to purchase them along with skills and knowledge needed to use can take advantage of it. In this situation, buying, selling, and trading the information would not be nationally or internationally meaningful any more, while they are considered over international market in different levels, and also national, local and ultimately the private and individual markets (Machlup, 2010: 22- 23).

\section{Geographical:-}

The information society has not only considered and defined by economists and socialists but also it has been considered from geographers who have a special attention to the location. In discussing the places, geographers emphasize on data networks linking the geographic locations to one another and believe that the networks have an interesting effect on the space and place (Doxia dis, 2013: 135).

\footnotetext{
${ }^{3}$-Fritz Machlub
} 


\section{Cultural:-}

As the matter of technology is very important in the rise of information community, cultural aspects are equally effective in causing it. Continuing television programs in several channels with high diversity, video films that are easy to prepare and rent from video clubs, disk recorders, CD, VCD, DVD that are available to everyone, personal computers that are available in every house, and " online " bases all and all have been very influential in the development of human cultural context, have given a cultural policy to the media users, and can be a model to the all of them. In other words, this level of information has culturally influenced on all aspects of life so that it has affected and transformed our identity and personality (Beniger, 2009: 369- 370). After getting familiar with the advent of the information society criteria, now we want to know what are the problems resulted from the society for us.

\section{Challenges from the information society:- Social discrimination:-}

In discuss to the social equality or inequality within information society, several issues can be noted and explained. As an example, unequal acquisition of wealth including income and assets as a challenge in the information society is sharply rising. The problem of social equality and inequality in this community that is based on equal or unequal access to information and media can be proposed in two levels. Theoretically, as explained in information society definition, it can be said that new informing media and modern communication networks make an easier and better dissemination and access to information and knowledge, so that in one hand they reduce the distance between the groups, individuals, and social classes within each country as well as reduce the gaps among nations on the other hand. But in practice, there is an information gap about unequal access to the media information, a process that increasingly on the rise (Kling, 2003: 116-117). The reality is that inequality in the information society has emerged and continued in a different form than the past. In an information society, providing computer and its accessories, telephone line and modem, access to satellite TV, and other new tools of communication is not possible for everyone in one hand, and knowledge and skills required using of internet and other means of communication is unequal in the other hand. There is no doubt both of these categories are exist within each country and between countries as an unequal way. In a sense, the access to above instruments in advanced nations and also the necessary skills to use them is very high compared with the least developed and developing countries as well as this inequality within each country is significant. Researchers like Jon van Dijk believe that we are in the information society observing a disparity in digital skills. A study at the year of 1997 in Germany shows that as further the moving from old communication tools that don't need special skills such as satellite TV, VCR, VCD, DVD, sending emails, electronic games and so on to the modern communication tools that require some necessary abilities, the lower the users who can utilize the technology severely. So that $85 \%$ of the Germany users were applying electronic games and satellite televisions and $89 \%$ were sending emails, but $22 \%$ were able to pay with their own Pin Cart or $15 \%$ were capable of paying their sums to ATM. Also in this year, only $23 \%$ could easily use Teletext of TV. Furthermore, the mentioned inequalities was also high among the young and old generations, those who were highly educated, and people without high academic degree (Bahrampour, Pishin: 34- 38). Other studies are also indicating unequal access to the above instruments. Most users of modern tools of information and communication are male, young, and well-trained, the people who are benefited from high income and living standards in the western countries. A survey conducted in the U.S. based on official figures between 1989- 1993 indicates that this inequality has been increased in all the above mentioned variables except gender. Also Van Dijk quotes that this issue is confirmed according to a number of other investigations carried out between 1995 to 1999 in the United States and Western Europe. The modern information and communication technologies divide the globe into two poles: one for those who are in a position to use fresh information and communication media, and other those in marginal areas and in the lower segments of the community not have access to this media (Castlls, 1385: 92).

\section{The expansion of social inequalities at the international level:-}

First of all, due to the lack of national telecommunication infrastructure and the economic growth to be low in developing countries, the expansion of the internet is much more expensive than their developed counterparts. For example, in the United States, each user should monthly pay $2 \$$ for internet connection, while the sum for a Ugandan user for the same interval is 92 \$. At the second, the countries such as latter, are faced with more fundamental problems like the lack of nutrition, connecting roads, employment, electricity, war, and unstable political systems. In these countries, there is no budget to fund the high cost of computer equipments and economically such facilities are only available for independent and top classes of the society. Thirdly, in these countries that Iran is also among them, because telecommunication companies holds the physical layer so this technology is monopolized by the government institutions and it is also in charge of the data communication lines. Hence, the lack of chance to compete owing to this aspect may result in a severe decline in the quality of internet 
services. In addition to the aforesaid, since most of the information on the internet is presented in English, unfamiliarity with the language is representing the lack of access to the information.

\section{The development of social inequalities at the national level:-}

Social, economic, and cultural difference within countries, the lack metropolises, marginalized and deprived areas of proportional and balanced distribution of social, cultural and construction funds, various income levels in the range of subcultures within a country, produce an environmental in which some people achieve the convenient facilities including to date information, and against them there is a group who despite having competence and sufficient talent, but they have been deprived of hardware and software facilities due to the lack of financial resources and training for them; the issue, as such, would broaden and deepen the social inequalities over the countries and among citizens (Saeedi, 1383: 11- 14).

\section{New identities:-}

The information society creates some new communities and identities. In a community relying on relations based on printing industry, TV, and telephone, the means of production is such that can turn the identity to a wise, useful and self-sufficient one. But in an information society meaning a society that is dominated by the electronic communications, a new mentalities, and multi-layered unstable identities can emerge. In the second media age, Mark Poster $^{4}$ asserts that in modern times when the society is dominated by the internet and electronic communications, these data and information, or more precisely, the virtual communities that make up the people's identity (Paster, 1377: 68- 69).

The modern information and communication facilities turn the identities into an entirely new position as a result of changes in the perceptions of modern man that is different and even contrary to the past. In virtual populations, the identity is in a transnational movement. Indeed, relation shaped relying on new communication and information devices reveal a perspective of understanding and a new understanding of subjectivity that are vitalized in the formulations of behavior and performance that are historically perceptible. The relations are effective in looking at human as a multilayered, variable, passive and fragmented phenomenon. A phenomenon which can design its own shaping such that fights with any confirmation of identity. Information society represents the unstable, changeable, flexible identity of the new man. There are many people, who have no proximity with neighbors, hometowns, townsmen, and even their own countrymen while have the same sense of identity with one person across the world. The emergence of virtual communities strongly threatens the national identity in the information society. In fact, individuals involved in such environments have usually at least one thing in common i.e. the interests that will bring them together. The benefits that are the same access to information build identity for them. An identity that is constantly changing and unstable. In a virtual community, people have a digital identity. So, territories, national and local language, national culture and race don't determine the identity for people any more, but the interests bringing them together will make their identity. In this modern society, information makes people's identity (Rabiei, 1387: 158-163).

\section{Social Distinction:}

The most important variable considered to the social uniformity is unification or social differentiation. As we know, socialization and individualization are two sides of modernity and the modern era. It means that the modern period has a dichotomy in the social structure, i.e. on the one hand leads to the individuals to be socialized and on the other hand strengthen the individualization of the people. At the times, radio and television consolidated the national and local societies with a limited network and then the fragmented and multi-faceted audiences have been produced by developing channels with plurality and diversity and the advent of cable television once again. At the end of this time, although audiences select a TV channel among a large number of ones, but TV owners and advertisers may still prefer the mass market. The new media are individualized ones, because they are based on personal interaction of human-computer. They are also the mass media that are used collectively, since their computers are all connected to the network. The new media respond to multiple requests and demands of users and audiences. Hence, the practical consequence the media's structural dichotomy can be defined through unifying and distinguishing trends in society. The result of media's structural dichotomy is the society's structural dichotomy to be generated. It seems to be more prominent the aforesaid duality manifestation for internet users and its related media and those who have access to the new information and communication devices. As these media can create some new human terms in that

\section{${ }^{4}$-Mark Poster}


people may be increasingly isolated, inactive, and claustral and gradually away from their own life's practical context. The communication researchers believe that the success of virtual communities is actually representative of the physical societies go to declined.

\section{Opportunities from information society:-}

The role of internet in research, innovation, and science:sinceall innovation and creativity are reflected on scientific survey, so the development of modern technologies and creativities are deemed to be achievements of information society. Among the most important things can be organized through internet is the professors and specialists from several disciplines to join to specific groups. Becoming a member of internet users in these groups, they can reach the most updated information in their specialties, because all members are in the route of scientific messages issued by one person. If the connecting lines have a good quality and in workplace stations two people or more are connected to the system with necessary facilities (video camera), they can also see each other and activities of the other side. Today, performing critical surgeries remotely with the participation of several specialties each of them from any point of the globe who can jointly monitor the operation or guide about that turned to a common trend in a number of well-equipped medical centers (Schement \& Curtis, 2005: 426- 427).

\section{Teleconferences:-}

Another form of research activity with a relatively common application in U.S. and countries in Western Europe is remote conference in that a number of experts (each is living one corner of the globe) exchange their views on the subjects of interests. This type of electronic conferences will become more popular in the future and it is probable the type of meeting will reduce the importance of face-to-face conferences (which is much more expensive) in a large scale. During recent decades, it found that the scientific journals to be useful for scientific communication among scientists and the number of them have been steadily increased around the world. However, due to the spread of the internet especially during the last 5 years, it appears not to be expected the growing movement as the previous years' did. The number of researchers who use the network for publishing their research results is frequently rising. They can give their produced data to all those who have access to the net and can also ask them in addition to expressing their opinions, send the similar scientific documents for them via the same channel, or have a continuous cooperation with each other (Smith \& Kollock, 2001: 50- 51).

Global symbiotic interaction and fluid and interplanetary identity formation:-

The fact is that the improved communication and information society development has lowered the gaps and created a kind of similarity especially between youth. Members of the United Nations Development Commission has reported that they have seen in their meetings in cities of various continents, the young people are very similar to each other and this similarity has been increased with the fading boarders and going to an information society and networked community. But it should be remembered that thanks to the expansion of communication means and media, if different societies deliberately and accurately act then they can use them for positive developments and find a world's healthy coexistence. Among issues that can show the other side of culture interaction using capability of information society include the fight against drugs at a global level, environmental protection, human solidarity, respect to the right of life, respect to personal privacy, restoring the rights of mothers and children, an emphasize on global justice, honoring human dignity and the rights of social and religious minorities, sustainable development and to allow for introducing other cultures and values. It seems that differentiation and society segmentation dominated by new communication and information media in Iran will be more than the social unity, integrity. Being satellite TV with the canals available in Iran and also being limited the number of Iran's TV canals with no diversity have caused the groups, classes and various Iranian ethnicities choose their favorite programs among satellite channels based on their own interests. So, the principle of media pluralism within information society has propelled the Iranians towards production and consumption of information, applications, and their own preferred channels and in this way, their cooperative, ethnic, and religious belongings are reinforced. Thus, what will be achieved is greater differentiation of the Iranian society as a whole and the collecting, religious, and ethic belongings to be further. The new communication media integrate these compatriots with the ones they exchange information and interact globally. As a result, different individuals, groups and nationalities are united together in a society other than their own real community (Azizi Ghomi, 1387: 30- 34).

\section{Islamic Republic of Iran government strategy at the basis of the information society:-}

However, in accordance with definition, purpose, issues and Iran's information society problems, they were used several variables from different sources, but it should be noted that considering the general foundations to move towards the information society is important from the perspective of government experts. Apart from the statements 
and views of government officials, some written documents are published from official institutions of the Islamic Republic that represent the practical procedures for those who like the information society. Among the matters are duties and the frame of function by the Supreme Council of Information, adopted by the Supreme Council of Cultural Revolution in the meetings 417 and 418, may and august 1377, and the aforementioned tasks have been defined as follow:

A. Policy making, planning, guidance and support the production, refinement, exchange and monitoring the information across the country within the framework of general policies of the system;

B. Designing and approval of comprehensive communication system of the country;

C. Developing the needed conditions for facilitating and accelerating the production, storage, organization, distribution, promotion, and application of information in several parts of cultural, scientific, social, economic, educational, technical, and research;

D. Coordinating the public and private sector activities in line with comprehensive communication system of the nation;

E. Formulating and adopting the concepts, definitions, regulations, and information standards needed to comprehensive information system. In the current year, there have been considerable changes on administrative structure in the ministry of Post, Telegraph and Telephone based on the structural changes to the underlying hardware. In the process, the monitoring structure on the ministry was benefited from three companies and subsection in order to equip of the country's relations: the firm of infrastructure communications, the firm of data communication, the firm of mobile communication. Two aspects aforesaid based on policy making in country's all-inclusive communication system and changes in the administrative structure of the Ministry of Post, Telegraph, and Telephone as well as to optimize utilization of hardware infrastructure, the strategic interests of the Islamic Republic of Iran in the foundation of information society are evident in a such way: the strategic plans considered based on development of users, information and communication technology (TEKFA) that is associated with different issues by observers. One of the major criticisms on the plan is the attitude to TEKFA trying to through a separate entity to the other institutions and organizations to inject information technology. In short, " for applying the information technology, there is no a separate and new entity". While it is obvious that given the current state of the information and communication technology, so conceiving the knowledge buds within Iranian society requires to power and the strong government support and of course the private sector (Hasani, 1392: 16- 21).

\section{Conclusion:}

As defined of a society, they have been noticed a number of different factors like relations, terms, and naturally cooperation. In this regard, the appropriate definition of community having terms has provided various thoughts for scholars; for instance, the professor Murteza Mutahhari says: a society is a multiple set of individuals who are merged because of determinism caused by a series of needs and float in a life under the influence of a range of ideas and ideals. Something that is clearly seen in this definition is cooperation in the effect of determinism, the phenomenon which is truly reminiscent of social phenomena from the perspective of Emile Durkheim, a view inclusive of a general or deterministic event. Edward Westermarck looks to the phenomenon based on the rule and relation of a western sociologist and says, "Community is a group of people who are living together". Here, the emphasis is on human collections with looking to the structure of participation and every single components of society to cooperate. The evident thing in both definitions is that, the structure of the collective people is deemed on the basis of a series of assistances. However, the factor of contribution, and to express themselves to what extent to be tolerated by the people, can resulted in the formation of different theories of society in human history successions, the theories that are included in the records of social thoughts. A case come from the term of information society that is proposed within sociology is based on the range of activities that are directly associated with producing, distributing, and applying the information and in this manner, the basis of the knowledge economy lies on the effective goods and services and communications become to alignment for practical function in society. From the eighties that William Martin discussed about the information society to date, several conflicts has remained to be assessed around the society, for example Daniel Bell is deemed the effect of information on social organization developments to be valid or Jean-Pierre is considered the post-industrial society as same as the information society and is pessimistically assumed this society as a stage of capitalism history that is struggled with its contradictions. In the information community, the matter which most needed to be defined is tangible factors influential on any society features. Among them, Mac Schesni sees the communication revolution and the rule of remote communications as inevitable factors in modern capitalist society. And/ or Dr. Manouchehr Mohseni who has tried the issue to investigated in terms of technical- social infrastructure in information society and states a special classification in the new variables for this kind of society. The infrastructures based on his theories are as 
follow: remote communication infrastructures, knowledge-related infrastructures, technological infrastructure relating the information with each other. Accordingly, William Martin in a final definition of the information society states: an information society is a one in which perspectives of social transformation and economic development is progressively dependent on information and the utilization of them. In continuance of Martin on the belief that the living standards, patterns of work and leisure, education system, and the labor market in such a society have been to a significant extent overshadowed by developments that occurred in the realm of information and knowledge. To support the issue, it can be pointed out the similarity of views Information High Council Document known as "a review of the new development" with the conclusion that: an integrated information society is recreation of all common and traditional procedures including business, education, . . . and even personal activities such as recreation, etc in a fresh context using information and communication technology. Also, Bill Gates, Microsoft CEO in his book at the beginning of the new millennium raises some questions facing with German bankers that in challenging with Iran's information society as a developing country are to be discussed for Iranian statesmen. Gates' questions in the new conditions are: do you believe that there is a time when trade shares and the most homes will be contained by web framework with a very fast communication? Do you think that most digital devices will be publicly? And finally, when do you think the process happen? Then he replies himself that, we must be prepared for change. Obviously, moving from semi-industrial and industrial society to information one demands requirements and infrastructures that are based culture building and new education in knowledge-driven society on.In a knowledge-driven society, training is based on information and communication technology in which there exist varied levels in the context of organizations advancement and the support of e-infrastructures activities. To what extent and how much longer this trend, the government as a dominant entity, and Iranian people as users of the new condition can be continued is subjected to changes in the level of investment at the national level and Iranian spirit and culture will accept it on the future.

\section{References:-}

1. Beck,U.(2009): Risk Society: Towards a New Modernity,Ed4, London: Sage.

2. Bedi,K.(2001),Government@net: New Governance Opportunities for India,New Delhi:Sage.

3. Beniger,J.(2009), The Control Revolution. Technological and Economic Origins of the Information Society,Ed11,Harvard University Press.

4. Doxiadis,C.(2013),Anthropopolis. City for Human Development ,New York University press.

5. Duff,A.(2000),Information Society Studies ,Routledge Research in Information Technology and Society, Routledge.

6. Graham,E.(2003), Turning points and commitment in post-divorce relationships,

7. Communication Monographs, Vol64.

8. Heeks, R.(2006), Reinventing Government in the Information Age,Ed6, London:Routledge.

9. Hillis, K.(2014),Digital Sensations, Minneapolis: University of Minnesota Press.

10. Kling,R.(2003), What is Social Informatics and Why Does it Matter? ,Journal D-Lib,Vol3.

11. Machlup, F. (2010), The Production and Distribution of Knowledge in the United States, Ed15,Princeton University Press.

12. Masuda,Y.(2000), The Information Society as Post-Industrial Society ,The World Future Society, Tokyo, IIS, Washington D. C.

13. Schement, J\&Curtis,T.(2005),Tendencies and tensions of the information age, Publishers, NewBrunswick University.

14. Smith,M\&Kollock,P. (2001),Communities in Cyberspace, London: Routledge.

15. Webster,F.(2007), Information Technology: A Luddite Analysis; Ablex: New Jersey.

16. Webster, F.(2002), Theories of the Information Society, 2nd Edition, London: Routledge. 